\section{Treatment of Relapsing Polychondritis with Tocilizumab}

\section{To the Editor:}

We read with interest the letter from Wallace and Stone ${ }^{1}$ describing a patient with relapsing polychondritis (RP) refractory to corticosteroids, cyclophosphamide, and tumor necrosis factor (TNF) blockers. The patient's biological inflammation and clinical symptoms of chondritis responded well after each tocilizumab (TCZ) infusion. We describe a somewhat different experience of TCZ efficacy in a patient with RP.

A 46-year-old woman was diagnosed with RP in 2000 with recurrent episodes of chondritis and mainly synovitis and tenosynovitis. After failure of prednisone, dapsone, several disease-modifying antirheumatic drugs, infliximab, and etanercept, she was successfully treated with anakinra (100 $\mathrm{mg} /$ day) beginning in $2007^{2}$. Because of clinical remission, she stopped anakinra injections in December 2010. She experienced relapse of symptoms in April 2012 [auricular chondritis, synovitis, and fatigue, with C-reactive protein (CRP) $5.4 \mathrm{mg} / \mathrm{dl}]$.

Because she did not want to return to daily injections, monthly infusions of TCZ $(8 \mathrm{mg} / \mathrm{kg})$ were initiated. A clinical improvement was observed during the first week after the first infusion, but did not last, and no effect was seen after the second, despite normalization of CRP. After 2 months, treatment was switched to anakinra, with a fair response after 2 weeks. Our patient did not develop a similar response profile to the one described by Wallace and Stone ${ }^{1}$, the 2 cases of Kawai, et $a l^{3}$, and that of Narshi and Allard ${ }^{4}$, all with positive results, mainly occurring soon after the first infusion. In the cases of Wallace and Stone and Kawai, elevated serum interleukin 6 (IL-6) levels were present, and this may account for a good clinical response to subsequent IL-6 blockade. IL-6 serum levels were not assessed in our case, but CRP was elevated. The therapeutic effect of TCZ in RP may be variable from one patient to another. This variability seems to exist for other biologic agents in this condition: a recent literature review ${ }^{5}$ analyzed 62 published cases treated with biologics for RP (43 with TNF blockers). Efficacy was reported in 27 patients, partial efficacy in 5 , and absence of efficacy in 29.
In RP, patients treated with biologic agents do not develop a uniform response, and individualization of predictive factors for good response to biologic agents would be helpful. For tocilizumab, elevated serum levels of IL-6 may be predictive factors for biological and clinical response.

DANIEL WENDLING, MD, PhD, Professor of Rheumatology; MARIE GODFRIN-VALNET, MD, Chef de Clinique Assistant; CLÉMENT PRATI, MD, PhD, Maitre de Conférences des Universités, Department of Rheumatology, CHRU de Besançon (University Teaching Hospital), Boulevard Fleming, F-25030 Besançon, France. Address correspondence to Dr. Wendling; E-mail: dwendling@chu-besancon.fr Dr. Wendling has received speaking fees and grants from Roche-Chugai, and was co-investigator of the OPTION study.

\section{REFERENCES}

1. Wallace ZS, Stone JH. Refractory relapsing polychondritis treated with serial success with interleukin 6 receptor blockade [letter]. J Rheumatol 2013;40:100-2.

2. Wendling D, Govindaraju S, Prati C, Toussirot E, Bertolini E. Efficacy of anakinra in a patient with refractory relapsing polychondritis. Joint Bone Spine 2008;75:622-4.

3. Kawai M, Hagihara K, Hirano T, Shima Y, Kuwahara Y, Arimitsu J, et al. Sustained response to tocilizumab, anti-interleukin-6 receptor antibody, in two patients with refractory relapsing polychondritis. Rheumatology 2009;48:318-9.

4. Narshi CB, Allard SA. Sustained response to tocilizumab, anti IL-6 antibody, following anti TNF- $\alpha$ failure in a patient with relapsing polychondritis complicated by aortitis. Rheumatology 2012;51:952-3.

5. Kemta Lekpa F, Kraus VB, Chevalier X. Biologics in relapsing polychondritis: A literature review. Semin Arthritis Rheum 2012;41:712-9.

J Rheumatol 2013;40:7; doi:10.3899/jrheum.130371 